\title{
Primary care physician satisfaction with patients diagnosed with depression. International Depression Project results from Colombia
} \author{
Satisfação do médico de cuidados primários com pacientes \\ diagnosticados com depressão. Resultados colombianos \\ do Projeto Internacional de Depressão
} Carlos Gómez-Restrepo, ${ }^{1}$ Adriana Bohórquez Peñaranda, ${ }^{1}$ Mayumi
Okuda Benavides, ${ }^{1}$ Jacky Fabian Gil Laverde, ${ }^{1}$ Natalia Sanchez Diaz ${ }^{1}$

\begin{abstract}
Objective: To characterize physician satisfaction with doctor-patient encounters, distinguishing between those involving patients diagnosed with depression and those involving patients without depression, as well as to determine the impact of an educational intervention aimed at improving the recognition and management of depression in primary care practice, in Bogotá, Columbia. Method: Physician satisfaction when treating outpatients in primary care centers was assesed by means of a questionnaire applied before and after the intervention. Results: The intervention was given to 18 physicians and 5 nurses. A total of 1650 questionnaires related to visits were collected in the first phase, and 1832 were collected in the second one. The percentage of patients diagnosed with depression increased from 5.9\% (95\% Cl: 4.8-7.1\%) before the intervention to 10.6\% (95\% Cl: 9.2-12.06\%) after. The total duration of the clinical encounter did not change significantly. The percentage of time spent on the physical problems/concerns of the patients decreased in both types of visits. Conclusions: Health professional satisfaction was the greatest when dealing with the physical problems of the patient. However, in both types of visits, the degree of satisfaction when dealing with the psychological aspects increased after the intervention.
\end{abstract}

Descriptors: Education, medical; Personal satisfaction; Primary health care; Ambulatory care; Depression

\begin{abstract}
Resumo
Objetivo: Caracterizar a satisfação dos clínicos com os encontros médico-paciente, distinguindo entre aqueles que envolvem pacientes diagnosticados com depressão e aqueles que envolvem pacientes sem depressão, bem como determinar o impacto de uma intervenção educacional visando a melhorar o reconhecimento e o gerenciamento da depressão na prática de atendimento primário em Bogotá, Colômbia. Método: A satisfação dos clínicos ao tratarem de pacientes ambulatoriais em centros de atendimento primário foi avaliada por meio de um questionário aplicado antes e depois da intervenção. Resultados: A intervenção foi ministrada a 18 clínicos e cinco enfermeiras. Um total de 1.650 questionários relativos às visitas foram coletados na primeira fase e 1.832 foram coletados na segunda fase. O percentual de pacientes diagnosticados com depressão aumentou de 5,9\% (IC 95\%: 4,8-7,1\%), antes da intervenção, para 10,6\% (IC 95\%/: 9,2-12,06\%) após a mesma. A duração total do encontro clínico não se modificou significativamente. O percentual de tempo despendido como os problemas/preocupações físicos dos pacientes decresceu em ambos os tipos de visitas. Conclusões: A satisfação dos profissionais de saúde foi mais alta ao tratarem dos problemas físicos dos pacientes. No entanto, em ambos os tipos de visitas o grau de satisfação ao tratarem dos aspectos psicológicos aumentou após a intervenção.
\end{abstract}

Descritores: Educação médica; Satisfação pessoal; Atenção primária à saude; Pacientes ambulatoriais; Depressão

\footnotetext{
1 Psychiatry and Mental Health Department, Department of Clinical Epidemiology and Biostatistics, Pontificia Universidad Javeriana School of Medicine, Bogotá, Colombia
}

World Psychiatric Association International Collaboration Project on Depression in Primary Care Practice (International Depression Project) financed by the International Clinical Epidemiology Network (INCLEN). Project: Development and Evaluation of a specific Educational Intervention aimed at improving depression recognition in primary care centers in Bogotá, financed by the Instituto Colombiano de Ciencia y Tecnología (Colciencias). National Program of Science and Technology in Health.

Financing: International Clinical Epidemology (INCLEN) and Colciencias

Conflicts of interest: None

Submitted: March 13, 2006

Accepted: June 21, 2006

\section{Correspondence}

Carlos Gómez Restrepo

Hospital Universitario de San Ignacio

Departmento de Epidemiología Clínica y Bioestadística. Dpto.

Psiquiatría y Salud Mental

Carrera $7 \mathrm{~N}^{\circ} 40-62$. Piso 2

Bogotá, Colombia

E-mail: cgomez@javeriana.edu.co 


\section{Introduction}

During the last few decades, the epidemiology of depression and its effects on populations have been studied. In 1996, the 'global burden of disease' study ${ }^{1}$ demonstrated the magnitude of this problem and the need to develop health policies aimed at minimizing its consequences. According to the study, unipolar depression will be the second leading cause of morbidity worldwide by the year 2020. In the year 2000, the World Health Organization (WHO) initiated the world mental health survey, and the results for Columbia were published by Posada et al. ${ }^{2}$ The authors reported a 15\% lifetime prevalence for mood disorders. In another study, published by Gómez-Restrepo et al., ${ }^{3}$ the twelve-month prevalence of depression (from 2000 to 2001) was calculated to be $10 \%$, which was higher than that estimated for the same period in other Latin American countries such as Brazil (7\%) and Mexico (4.5\%).4-5

There is substantial evidence that detecting and managing depression at the primary care level is important. ${ }^{6-7}$ In a review of depression in the community, Tylee recommend that primary care physicians maintain a high level of suspicion of mental illnesses when treating patients that seek help for physical and social problems. ${ }^{8}$ The author lists the following considerations:

1) In most clinical encounters, patients with psychiatric disorders initially complain only of somatic symptoms and do not mention psychological problems until the end of the visit;

2) Physicians who have had more years of schooling and are aware of appropriate concepts regarding minor psychiatric illnesses classify the psychiatric disorders of their patients with greater consistency;

3) Physicians who conduct longer interviews are no better at detecting mental problems, although other studies have shown that the probability of psychological problems being detected increases when visits are longer;

4) Physician inability to detect depression might be due in part to a lack of knowledge of the depressive symptoms, to greater concern for the organic illness and to a failure to evaluate the symptoms necessary to make the diagnosis during a clinical encounter. ${ }^{8}$

The major determinants of physician satisfaction with the clinical encounter include the professional skills of the physician and the quality of the interpersonal interaction with the patient. Daghio et al. explored the different aspects of the clinical encounter related to the doctor-patient relationship. ${ }^{9}$ The investigators expected to analyze the diagnostic-therapeutic process and physician satisfaction in terms of professional competence and the degree to which physicians are satisfied with their own communication skills and ability to empathize. In the different doctor-patient models they examined, they found that physician satisfaction with the encounter was highly influenced by professional competence and self-esteem. ${ }^{9}$ The authors found that the following factors were highly predictive of physician satisfaction with the encounter: patient compliance with medical advice/treatment regimens; personal and professional satisfaction of the part of the physician; patient respect for the professional abilities of the physician; fewer questions regarding the diagnosis (reported by the patients as well as by the physicians); and aspects related to uncertainties reported by the physician in terms of diagnosis and treatment.

The quality of the clinical encounter and its outcomes can be considered to be determined by multiple factors: physician level of knowledge; patient capacity to communicate symptoms; the duration of the encounter; physician satisfaction; the quality of the doctor-patient relationship; and the environment in which the encounter takes place. These factors can be applied to the management of patients with psychological symptoms, especially those with depressive disorder. This article presents some of the results of the International Depression Project, and its purpose is to examine satisfaction with various aspects of clinical encounters (with depressed patients as well as with non depressed patients) on the part of the primary care health professionals that participated in an educational intervention.

\section{Method}

In order to develop and evaluate a clinical educational intervention specifically designed to improve the recognition and management of depression in primary care practice, an educational intervention developed for depressive disorders was adapted to the specific needs and opportunities of primary care treatment in Bogotá, Columbia. This study was part of a multicentric project developed simultaneously in Chennai, India and in Beijing, China.

The study sample was calculated for the comparison of interobserver kappa variability (with two observers) for each country. In most cases, the sample size was based on the country-specific data available in the WHO-sponsored Psychological Problems in General Health Care (PPGHC) study. ${ }^{10}$ Since some of the countries involved in the study had not participated in the WHO study, data from similar countries were used.

The models used to calculate the the PPGHC study ${ }^{10}$ sample sizes in each country included the Kappa values for depression and mixed anxiety/depression calculated for primary care health professionals vs. the Composite International Diagnostic Interview (CIDI) diagnosis and the specific prevalence for depression in each country found in the two-step sampling evaluated using the CIDI in the PPGHC study (the screening process used in the PPGHC study is the same as that used in the present study).

Training in depressive disorders was provided to a group of health professionals working in outpatient primary care centers belonging to entidades promotoras de salud (EPS, health promoter entities) in the city of Bogotá, which were considered representative of the primary health care providers in the urban areas of the country.

Two primary care facilities were chosen on the basis of convenience. The logistical problems involved in working in rural areas limited the study to urban centers (where $75 \%$ of all Colombian residents live). In urban centers, primary care is provided in a number of different settings, but most of the treatment is provided at primary care centers and outpatient clinics of general hospitals. In the year 2000, meetings with different private and public entities were held in order to choose EPS primary care centers that served a broad segment of the urban population and were located at strategic points around the city. The fact that the users lived within the wide zone of influence of these centers was taken into account.

The selected centers were representative of the urban facilities that provide services at a primary care level. This means that the range of services, the degree of professionalism, patient load, patient characteristics and coverage of the population in these centers are similar to those seen in the facilities that typically provide health care in the urban areas of Colombia. The number of health care centers chosen was determined by the total number of patients that would have to be screened in order to reliably evaluate the prevalence of depression. 
These centers presented characteristics that allowed a satisfactory number of patients to be selected on a daily basis, doctors had job stability, and the setting made it possible for the research team to be present without interrupting the regular activities of the center.

The educational intervention given to the physicians involved four stages:

1) In each primary care center, a detailed, observational "situational analysis" was conducted of the current methods of evaluation and treatment of the patients was conducted, as well as of the knowledge and attitudes regarding depression on the part of the patients and on the part of the health professionals. The results of the observational evaluations informed negotiations with the center directors and health care providers regarding the feasibility, acceptability and implementation of changes in the methods of evaluation and management of patients with potential psychological problems.

2) Training was given based on, but not limited to, the materials created by the World Psychiatric Association. The objective was to help each center become accustomed to providing new services, as well as to increase physician skill in convincing patients to accept such services.

3) An educational program and consulting services were provided by mental health professionals that aided the centers in the implementation and evaluation of the new procedures and supervised the treatment proposed by the physicians in treating depressed patients.

Based on discussions of the methodology, the collaborative group recommendations and the information gathered in the initial evaluation, an educational intervention was structured as a theoretical and practical activity adapted to the cultural context, the opportunities and needs of the physicians that participated in the study. The intervention presented the following characteristics:

1) Eight-hour duration;

2) A teaching team composed of two health care professionals;

3) Use of vignettes of cases of depression in a primary care context;

4) Approximately one-third of the time was set aside for the case discussion;

5) Role-playing games for the development of patient interviews.

In addition to the evaluation of various aspects related to the clinical encounter, ${ }^{11-12}$ all of the patients presenting physiciandiagnosed depression were submitted to a confirmatory secondstage interview, which was a structured interview derived from the CIDI. In addition, second-stage interviews were performed in the other groups of patients according to the risk calculated from the results of a screening test for depression. The screening test consisted of two questions: "Within the last month, did you feel sad, blue or depressed every day for a period of two weeks or more?"; and "Within the last month, was there a period of two weeks or longer during which you lost interest in things such as work or hobbies or in things you usually like to do for fun?" The study sample was consisted of $10 \%$ low risk group (no affirmative answers); $20 \%$ for moderate risk (one affirmative answer) and 50\% for high risk group (both answers affirmative). In the first and second phases, 369 patients and 604 patients, respectively, were deemed eligible. Finally, 151 first-phase patients and 197 second-phase patients agreed to participate in the secondstage interview.
There were 18 physicians and 5 nurses who participated in the study. In both phases, they received the training and filled out the questionnaires. The instrument was applied in an identical manner before and two months after the educational intervention. Participating patients were seen by an attending physician or nurse. After the visit, the health professional was asked to answer the questionnaire and to make a report of the visit, stating whether or not a diagnosis of depression was made, evaluating the health status of the patient and describing the prescribed management (if a diagnosis had been made). Prior to receiving the questionnaire, the health professionals were unaware of which patients had decided to participate.

Among the evaluations and outcome measures of the intervention, an instrument (a questionnaire) was developed to evaluate physician satisfaction with the clinical encounter.

The questionnaire was designed by the international collaboration group (composed of investigators from China, India and Colombia), was filled out by the participating health professionals and included the following items:

1) Chief complaint;

2) Major symptoms classification;

3) Duration of the clinical encounter;

4) Percentage of the encounter dedicated to physical, psychological and social problems;

5) Physician/health professional satisfaction with:

a) Amount of time dedicated to the physical, psychological and social problems of the patient;

b) Information provided by the patient;

c) Understanding of the problems of the patient;

d) Management of the various types of problems;

e) Patient understanding of the explanations given and recommendations made by the physician;

f) The encounter in general.

In addition, the variables related to physician satisfaction resulting from clinical encounters with patients diagnosed with depression on behalf of the physician confirmed by the secondstage interview before and after the intervention were described. For the comparison of qualitative variables, the chisquare test or Fisher's exact test was used, and Student's ttest was used to compare quantitative variables among independent groups.

\section{Statistical analysis}

After all of the data had been collected, the information was fed into a database (Microsoft Access ${ }^{\circledR}$ ), and the cleanup was performed manually. The SAS 8.0 and STATA 8.2 programs were used for the analysis of the data. Initially, a descriptive analysis of the post-visit questionnaire variables was made comparing patients with depression to patients without depression, as well as comparing the pre-training period to the post-training period. In addition, data for the subgroup of patients submitted to the second-stage interview for the confirmation of the diagnosis of depression were analyzed. The level of statistical significance was set to $5 \%$. When appropriate, 95\% confidence intervals (95\% Cls) are given.

The statistical analysis included the description of the characteristics of the physicians participating and not participating in the study, together with the description of the patients studied, the classification of the major symptoms of the patients that completed the second-stage interview, as well as the amount of time dedicated to physical, psychological and social problems during each encounter, before and after the educational intervention. Data are presented as means \pm standard deviations. 


\section{Ethical considerations}

The study was approved by the Ethics Committees of the Universidad Javeriana School of Medicine and of the EPS that owned the primary care health centers. Participants gave written informed consent to participate and to receive information related to their visits and medical charts.

\section{Results}

Among the health professionals that participated in the study, the mean age was $34.1 \pm 4.7$ years (range, $25-43$ years), compared with $33.1 \pm 4.5$ years (range, $27-44$ years) among those that did not participate. The difference between these two groups was not statistically significant.

The characteristics of the patients participating in the preand post-intervention phases are presented in Table 1.

Prior to the intervention, the questionnaire was applied to 18 physicians and 5 nurses in relation to a total of 1650 visits. At two months after the intervention, the same questionnaire was applied to these same health professionals in relation to a total of 1832 visits. In the pre-intervention phase, health care professionals made a diagnosis of depression in $97(5.9 \%)$ of the patients evaluated $(95 \% \mathrm{Cl}$ : 4.8-7.1\%). In the pre-intervention phase, the same diagnosis was made in $195(10.6 \%)$ of the patients $(95 \%$ $\mathrm{Cl}: 9.2-12.06 \%)$, the difference between the two phases being statistically significant $(p<0.05)$. The second-stage interview, as previously described, was used in 151 firstphase patients and in 197 second-phase patients; the diagnosis was confirmed in 83 of the former and in 77 of the latter.

When health care professionals classified the symptoms that prompted the visit, it was found that psychological symptoms constituted the motivation for a low percentage of patients in both phases and in either type of patient. After the intervention, the health care professionals identified a greater percentage of patients with depression seeking treatment for somatic symptoms probably due to psychological illness.

On average, the duration of the encounter was longer for depressed patients than for patients who were not depressed.
The mean pre-intervention and post-intervention durations of the encounter were $16.3 \pm 4.6 \mathrm{~min}$ and $16.2 \pm 2.2 \mathrm{~min}$, respectively, for patients diagnosed with depression, compared with $14.9 \pm 3.1 \mathrm{~min}$ and $16.2 \pm 2.2 \mathrm{~min}$, respectively, for non depressed patients.

Prior to the intervention, the mean percentage of time dedicated to the physical problems of the patients was $56.4 \pm 26.04 \%$ for those diagnosed with depression and $86.9 \pm 23.9 \%$ for those without depression, compared with $53.5 \pm 21.5 \%$ and $66.4 \pm$ $33.4 \%$, respectively, after the intervention. A statistical difference was found only in the comparison between the pre- and postintervention times for the patients without depression.

Prior to the intervention, the mean percentage of time dedicated to the psychological problems of the patients was $28.3 \pm 2.19 \%$ for those diagnosed with depression and 6.9 $\pm 12.1 \%$ for those without depression, compared with $32 \pm$ $18.5 \%$ and $10.6 \pm 12.2 \%$, respectively, after the intervention. No statistical differences were found in terms of the time dedicated to psychological problems. The percentage of time dedicated to the different aspects of the visit for patients with and without depression, as determined using the second-stage interview, is presented in Table 3.

Prior to the intervention, the mean percentage of time dedicated to the social problems of the patients was $9.1 \pm$ $10.4 \%$ for those diagnosed with depression and $3.68 \pm 8.1 \%$ for those without depression, compared with $8.53 \pm 10.4 \%$ and $3.52 \pm 5.9 \%$, respectively, after the intervention. The difference between the pre- and post-intervention values was not statistically significant.

The overall satisfaction with the clinical encounter was 89\% for both patient groups (with and without depression) prior to the intervention, whereas the post-intervention values were $81 \%$ for the encounters with depressed patients and 91\% for those with nondepressed patients. Physician satisfaction with the different aspects of the encounter is shown in Tables 4 and 5 , the former related to encounters involving patients with physician-diagnosed depression and the latter related to those involving patients whose physician-diagnosed depression was confirmed through the second-stage interview.

Table 1.1 - Characteristics of the patients studied

\begin{tabular}{|c|c|c|c|}
\hline & Before the educational intervention & After the educational intervention & $\mathbf{p}$ \\
\hline Number of patients & 1647 & 1832 & \\
\hline Age $^{\star}$ & $36.2 \pm 13.89$ (range, $15-88$ ) & $41.3 \pm 16.04$ (range, $15-89$ ) & $<0.001$ \\
\hline \multicolumn{4}{|l|}{ Gender } \\
\hline Female, n (\%) & $433(26.29 \%)$ & $642(35.04 \%)$ & $<0.001$ \\
\hline Male, $\mathrm{n}(\%)$ & $1214(73.71 \%)$ & $1190(64.96 \%)$ & $<0.001$ \\
\hline Educational level (years of study) ${ }^{\star}$ & $10.20 \pm 4.21$ & $9.54 \pm 4.34$ & $<0.001$ \\
\hline First visit, n (\%) & $131(7.95 \%)$ & $176(9.61 \%)$ & $<0.001$ \\
\hline Last visit within a week or less, $\mathrm{n}(\%)$ & $250(13.53 \%)$ & $158(8.62 \%)$ & $<0.001$ \\
\hline
\end{tabular}

"Mean \pm standard deviation

Table 1.2 - Characteristics of health professionals that participated and that did not participate in the study

\begin{tabular}{lcc}
\hline & Received the educational intervention & $\begin{array}{c}\text { Did not receive the educational } \\
\text { intervention }\end{array}$ \\
\hline Profession & & \\
Physician, $n(\%)$ & $18(78.3 \%)$ & $48(98 \%)$ \\
Nurse, $n(\%)$ & $5(21.7 \%)$ & $1(2 \%)$ \\
Gender & $13(56.5 \%)$ & $29(59.2 \%)$ \\
Female, $n(\%)$ & $10(43.5 \%)$ & $20(40.8 \%)$ \\
Male, $n(\%)$ & $34.1 \pm 4.7($ range, $25-43)$ & $33.1 \pm 4.4($ range, $27-44)$ \\
Age $^{*}$ & & 0.999 \\
\hline
\end{tabular}

"Mean \pm standard deviation 
Table 2 - Classification of major symptoms for the patients evaluated

\begin{tabular}{|c|c|c|c|c|c|c|c|c|c|}
\hline \multirow[t]{3}{*}{ Symptom classification } & \multicolumn{4}{|c|}{ Before the educational intervention } & \multicolumn{4}{|c|}{ After the educational intervention } & \multirow[t]{3}{*}{$\mathbf{P}^{*}$} \\
\hline & \multicolumn{2}{|c|}{ With depression } & \multicolumn{2}{|c|}{ Without depression } & \multicolumn{2}{|c|}{ With depression } & \multicolumn{2}{|c|}{ Without depression } & \\
\hline & $n^{*}$ & $\%$ & $n^{*}$ & $\%$ & $n^{*}$ & $\%$ & $\mathrm{n}^{*}$ & $\%$ & \\
\hline Somatic symptoms likely due to physical illness & 20 & 29.4 & 801 & 79.5 & 79 & 40.7 & 1254 & 78.7 & $<0.001$ \\
\hline Somatic symptoms without explanation & 8 & 11.7 & 36 & 3.5 & 26 & 13.4 & 53 & 3.3 & 0.095 \\
\hline $\begin{array}{l}\text { Somatic symptoms likely due to psychological } \\
\text { illness }\end{array}$ & 34 & 50 & 45 & 4.4 & 75 & 38.6 & 30 & 1.8 & $<0.001$ \\
\hline Only psychological symptoms & 4 & 5.8 & 2 & 0.2 & 10 & 5.1 & 2 & 0.1 & 0.569 \\
\hline No symptoms at the time & 2 & 2.9 & 123 & 12.2 & 4 & 2.0 & 253 & 15.8 & 0.638 \\
\hline Total & 68 & 100 & 1007 & 100 & 194 & 100 & 1592 & 100 & \\
\hline Number of patients & \multicolumn{4}{|c|}{1075} & \multicolumn{4}{|c|}{1786} & \\
\hline Missing & \multicolumn{4}{|c|}{575} & \multicolumn{4}{|c|}{46} & \\
\hline
\end{tabular}

"number of questionnaire items answered

$+p$-value for chi-square test or Fisher's exact test

\section{Discussion}

One limitation of the present study is that a significant proportion of the physicians did not fill out the questionnaires, probably due to time constraints, lack of interest in the study or low self-esteem in relation to their professional activities. After the educational intervention, the participants exhibited greater interest in the study, and the answer rate therefore improved, although the answers were likely conditioned by their interest.

To date, there have been no studies using this format to evaluate physician satisfaction with the clinical encounter. Daghio et al. evaluated the doctor-patient relationship from the point of view of the doctor. ${ }^{12}$ However, those authors did not evaluate the various elements of the clinical encounter, as we have done in the present study. ${ }^{12}$

Discriminating between the encounters involving depressed patients and those involving non depressed patients, it was found that, in both types of encounters, the time dedicated to psychological concerns and problems increased after the educational intervention. Taking into account the high prevalence of depression in our population, we suggest that this could increase the likelihood that physicians will detect mental health problems in patients treated at primary care centers, which in turn could have a beneficial impact in public health.

In the present study, a considerable percentage of the patients diagnosed with depression sought treatment due to somatic symptoms, and the number of those patients identified as such increased after the physicians had been trained. We found that not only was this rate of recognition increased among the health professionals receiving the training but that those professionals also found fewer depressed patients seeking health care in the group of patients whose somatic symptoms were probably due to psychological illness. This finding could be explained by an increase in the sensitivity of the health professionals in detecting more depressed patients among those who sought treatment for somatic symptoms due to a physical illness and an increase in the specificity of the health professionals in the clinical encounters with patients seeking treatment for somatic symptoms that were likely due to psychological illness that did not meet the criteria for depression. Nevertheless, this difference was not found in the subgroup of patients submitted to the second-stage interview.

In both types of visits and during both phases, the time dedicated to physical problems decreased, although the satisfaction with the time used to solve these problems remained high. Although satisfaction with the time dedicated to psychological problems and concerns increased significantly after the intervention for both types of visits, the increase was especially pronounced for visits involving patients without depression.

In the subgroup of patients for whom the participating physicians did not make a diagnosis of depression, we observed that all of the changes were statistically significant. However, it is of note that, in general, the overall level of satisfaction with the different aspects of the encounters involving patients in this subgroup remained high, and that only some of the differences were clinically relevant. Among such clinically relevant differences were those related to psychological problems (the time dedicated to psychological problems and information provided by the patient in relation to those problems, as well as the understanding and management of such problems on the part of the physician) and to social problems (management and understanding on the part of the physician). These findings could be due to the size of the subgroup.

In the subgroup of patients with physician-diagnosed depression, only the increase in dissatisfaction with patient understanding of the explanations/recommendations given by the physician and with the perception of the willingness of the patient to follow them were found to be significant. In addition, the fact that a statistically significant increase in overall dissatisfaction with encounters involving such patients was found might be attributable to the previously mentioned changes.

Table 3 - Time distribution in the clinical encounters with patients submitted to the structured second-stage interview

\begin{tabular}{|c|c|c|c|c|}
\hline \multirow[b]{2}{*}{ Aspect* } & \multicolumn{2}{|c|}{$\begin{array}{l}\text { Before the educational intervention } \\
\qquad(n=151)\end{array}$} & \multicolumn{2}{|c|}{$\begin{array}{l}\text { After the educational intervention } \\
\qquad(n=197)\end{array}$} \\
\hline & SSI-confirmed depression & $\begin{array}{l}\text { Depression not confirmed } \\
\text { in the SSI }\end{array}$ & SSI-confirmed depression & $\begin{array}{l}\text { Depression not confirmed } \\
\text { in the SSI }\end{array}$ \\
\hline Physical problems & $78.5 \mathrm{~min}$ & $72.8 \mathrm{~min}$ & $58 \mathrm{~min}$ & $65.2 \mathrm{~min}$ \\
\hline Psychological problems & $11.2 \mathrm{~min}$ & $17.9 \mathrm{~min}$ & $16.9 \mathrm{~min}$ & $20 \mathrm{~min}$ \\
\hline Social problems & $3.2 \mathrm{~min}$ & $7.5 \mathrm{~min}$ & $5.1 \mathrm{~min}$ & $5.3 \mathrm{~min}$ \\
\hline
\end{tabular}

-Presented as the amount of time dedicated to each aspect

SSI: second-stage interview 
Table 4 - Pre- and post-intervention health professional satisfaction with clinical encounters involving patients with physician-diagnosed depression

\begin{tabular}{|c|c|c|c|c|c|c|c|c|c|}
\hline \multirow[b]{4}{*}{ Item } & \multicolumn{8}{|c|}{ Health professional satisfaction } & \multirow[t]{4}{*}{$\mathbf{p}$} \\
\hline & \multicolumn{4}{|c|}{ Before the intervention $(n=97)$} & \multicolumn{4}{|c|}{ After the intervention $(n=195)$} & \\
\hline & \multicolumn{2}{|c|}{ Satisfied } & \multicolumn{2}{|c|}{ Unsatisfied } & \multicolumn{2}{|c|}{ Satisfied } & \multicolumn{2}{|c|}{ Unsatisfied } & \\
\hline & $\mathrm{n}^{*}$ & $\%$ & $n^{*}$ & $\%$ & $n^{*}$ & $\%$ & $n^{*}$ & $\%$ & \\
\hline Time dedicated to the physical concerns/problems & 80 & 87.91 & 11 & 12.09 & 186 & 95.39 & 9 & 4.62 & 0.02 \\
\hline Time dedicated to the psychological concerns/problems & 52 & 58.43 & 37 & 41.57 & 143 & 73.33 & 52 & 26.67 & 0.01 \\
\hline Overall duration of the clinical encounter & 74 & 84.09 & 14 & 15.91 & 154 & 80.21 & 38 & 19.79 & 0.33 \\
\hline Information provided by the patient regarding the physical problems & 85 & 90.11 & 9 & 9.89 & 187 & 95.90 & 8 & 4.10 & 0.06 \\
\hline Information provided by the patient regarding the psychological problems & 58 & 64.44 & 32 & 35.56 & 137 & 70.26 & 58 & 29.74 & 0.32 \\
\hline Understanding of the physical problems & 84 & 92.31 & 7 & 7.69 & 181 & 92.82 & 14 & 7.18 & 0.88 \\
\hline Understanding of the psychological problems & 63 & 70.0 & 27 & 30.0 & 150 & 76.92 & 45 & 23.08 & 0.21 \\
\hline Management of the physical problems & 83 & 91.21 & 8 & 8.79 & 182 & 93.34 & 13 & 6.67 & 0.53 \\
\hline Management of the psychological problems & 62 & 68.89 & 28 & 31.11 & 146 & 74.87 & 49 & 25.13 & 0.28 \\
\hline Management and understanding of the social problems related to the illness & 70 & 76.92 & 21 & 23.08 & 147 & 75.78 & 47 & 24.23 & 0.85 \\
\hline Patient understanding of the explanations given/recommendations made & 81 & 89.01 & 10 & 10.99 & 156 & 80.0 & 39 & 20.0 & 0.06 \\
\hline Patient willingness to follow the recommendations & 81 & 90.0 & 9 & 10.0 & 152 & 77.95 & 43 & 22.05 & 0.01 \\
\hline The clinical encounter in general & 81 & 89.01 & 10 & 10.99 & 159 & 81.54 & 36 & 18.46 & 0.12 \\
\hline
\end{tabular}

"number of questionnaire items answered by the physicians

Notably, among patients with depression whose diagnosis was confirmed through the second-stage interview, we found significant changes in all of the items on the questionnaire. We suggest that physicians experienced uncertainty when making the diagnosis of depression, which might have affected satisfaction with the various aspects of the encounter, since, for the truly depressed patients (patients presenting positive results in the confirmatory secondstage interview), a statistical increase in satisfaction was found for the various encounter components evaluated.

Although satisfaction regarding the various psychological aspects of the patients (information provided by the patient, understanding/management of the problems) increased for both types of patients, physician dissatisfaction was greater for visits involving depressed patients. Finally, these postintervention differences in physician satisfaction with the management of psychological problems did not affect the overall duration of the encounter.

\section{Conclusions}

Health professional satisfaction with the information given by the patient, as well as with the understanding and management of the patient problems, was greater when dealing with the physical problems of patients, whether in visits involving patients diagnosed with depression or in visits involving those without depression.

In dealing with the psychological problems of the patient, health professional satisfaction for both types of visits increased after those professionals received an educational intervention regarding depressive disorders.

\section{Acknowledgments}

The authors are grateful to INCLEN and Conciencias for their financial support.

Table 5 - Pre- and post-intervention health professional satisfaction with clinical encounters involving patients with depression whose diagnosis was confirmed in a structured second-stage interview

\begin{tabular}{|c|c|c|c|c|c|c|c|c|c|}
\hline \multirow[b]{4}{*}{ Item } & \multicolumn{8}{|c|}{ Health professional satisfaction } & \multirow[t]{4}{*}{$\mathbf{p}$} \\
\hline & \multicolumn{4}{|c|}{ Before the intervention $(n=83$ ) } & \multicolumn{4}{|c|}{ After the intervention $(n=77)$} & \\
\hline & \multicolumn{2}{|c|}{ Satisfied } & \multicolumn{2}{|c|}{ Unsatisfied } & \multicolumn{2}{|c|}{ Satisfied } & \multicolumn{2}{|c|}{ Unsatisfied } & \\
\hline & $\mathbf{n}^{*}$ & $\%$ & $\mathbf{n}^{*}$ & $\%$ & $\mathbf{n}^{*}$ & $\%$ & $\mathbf{n}^{*}$ & $\%$ & \\
\hline Time dedicated to the physical concerns/problems & 44 & 80.0 & 11 & 20.0 & 76 & 98.7 & 1 & 1.3 & 0.0002 \\
\hline Time dedicated to the psychological concerns/problems & 25 & 51.0 & 24 & 48.9 & 63 & 82.9 & 13 & 17.1 & 0.0001 \\
\hline Overall duration of the clinical encounter & 41 & 78.8 & 11 & 21.1 & 70 & 92.1 & 6 & 7.89 & 0.0299 \\
\hline Information provided by the patient regarding the physical problems & 47 & 83.9 & 9 & 6.07 & 74 & 96.1 & 3 & 3.90 & 0.0155 \\
\hline Information provided by the patient regarding the psychological problems & 29 & 58.0 & 21 & 42.0 & 63 & 82.9 & 13 & 17.1 & 0.0021 \\
\hline Understanding of the physical problems & 47 & 3.93 & 9 & 16.07 & 75 & 97.4 & 2 & 2.6 & 0.005 \\
\hline Understanding of the psychological problems & 32 & 65.3 & 17 & 34.6 & 64 & 84.2 & 12 & 15.7 & 0.014 \\
\hline Management of the physical problems & 48 & 85.7 & 8 & 14.29 & 74 & 96.1 & 3 & 3.9 & 0.0317 \\
\hline Management of the psychological problems & 31 & 63.3 & 18 & 36.7 & 62 & 82.7 & 13 & 17.3 & 0.0142 \\
\hline Management and understanding of the social problems related to the illness & 39 & 72.2 & 15 & 27.7 & 69 & 90.7 & 7 & 9.2 & 0.0054 \\
\hline Patient understanding of the explanations given/recommendations made & 42 & 80.8 & 10 & 19.2 & 73 & 94.8 & 4 & 5.19 & 0.0119 \\
\hline Patient willingness to follow the recommendations & 44 & 81.5 & 10 & 18.5 & 72 & 93.5 & 5 & 6.49 & 0.034 \\
\hline The clinical encounter in general & 48 & 87.3 & 7 & 12.73 & 72 & 93.5 & 5 & 6.49 & 0.219 \\
\hline
\end{tabular}




\section{References}

1. Murray CJ, Lopez AD, editors. The global burden of disease: a comprehensive assessment of mortality and disability from diseases, injuries, and risk factors in 1990 and projected to 2020. Harvard School of Public Health on behalf of the World Health Organization and the World Bank. Cambridge, MA: Harvard University Press; 1996.

2. Posada JA, Aguilar SA, Magana CG, Gomez LC. Prevalencia de trastornos mentales y uso de servicios: resultados preliminares del Estudio Nacional de Salud Mental. Colombia 2003. Rev Colomb Psiquiatr. 2004;33(3):241-62.

3. Gomez-Restrepo C, Bohorquez A, Pinto D, Gil JF, Rondon M, DiazGranados N. Prevalencia de depresión y factores asociados con ella en la población Colombiana. Rev Panam Salud Publica. 2004;16(6):378-86.

4. Andrade L, Walters EE, Gentil V, Laurenti R. Prevalence of ICD-10 mental disorders in catchment area in the city of Sao Paulo, Brazil. Soc Psychiatry Psychiatr Epidemiol. 2002;37(7):316-25.

5. Caraveo-Anduaga J, Colmenares E, Saldivar G. Estudio clínicoepidemiológico de los trastornos depresivos. Salud Mental. 1999;22(2):7-17.

6. Johnson J, Weissman MM, Klerman GL. Service utilization and social morbidity associated with depressive symptoms in community. JAMA. 1992;267(11):1478-83.

7. Andrews G, Carter GL. What people say about their general practioners treatment of anxiety and depression. Med J Aust. 2001;175 Suppl:S48-51.

8. Tylee A. Depression in the community: physician and patient perspective. J Clin Psychiatry. 1999;60 Suppl 7:12-6, discussion: 17-8

9. Daghio MM, Ciardullo AV, Cadioli T, Delvecchio C, Menna A, Voci C, Guidetti P, Magrini N, Liberati A. GP's satisfaction with the doctorpatient encounter: findings from a community-based survey. Fam Pract. 2003;20(3):283-8.

10. Sartorius N, Ustun TB, Costa e Silva JA, Goldberg D, Lecrubier Y, Ormel J, Von Korff M, Wittchen HU. An international study of psychological problems in primary care. Preliminary report from the World Health Organization Collaborative Project on 'Psychological Problems in General Health Care'. Arch Gen Psychiatry. 1993;50(10):819-24.

11. Riveros M, Bohorquez A, Gomez-Restrepo C, Okuda M Conocimientos sobre la depresión en pacientes que asisten a centros de atención primaria en Bogotá, Colombia. Resultados Colombianos del Proyecto Internacional de Depresión. Rev Colomb Psiquiatr. 2006;35(1):9-22.

12. Gomez-Restrepo C, Bohorquez A, Gil F, Perez V. Conocimiento sobre los trastornos depresivos y evaluación de una intervención educativa aplicada a médicos de atención primaria en Bogota, Colombia. Resultados Colombianos del Proyecto Internacional de Depresión. Rev Colomb Psiquiatr. 2005;34(2):220-41. 